\title{
Computed tomography morphologic features of pulmonary adenocarcinoma with brain/bone metastasis
}

\author{
Ki-Eun Hwang ${ }^{1}$, Su-Jin Oh${ }^{1}$, Chul Park ${ }^{1}$, Se-Jeong Jeon ${ }^{2}$, Jeong-Mi Lee ${ }^{3}$, Byong-Ki Cha ${ }^{4}$, Kwon-Ha Yoon ${ }^{2}$, \\ Eun-Taik Jeong ${ }^{1}$, and Hak-Ryul Kim ${ }^{1}$
}

\begin{abstract}
${ }^{1}$ Department of Internal Medicine, Institute of Wonkwang Medical Science, Departments of ${ }^{2}$ Radiology and ${ }^{3}$ Public Health, Wonkwang University School of Medicine, Iksan; ${ }^{4}$ Department of Thoracic and Cardiovascular Surgery, Chonbuk National University Medical School, Jeonju, Korea
\end{abstract}

Received: April 21, 2016 Revised : September 30, 2016 Accepted: November 7, 2016

\section{Correspondence to}

Hak-Ryul Kim, M.D.

Department of Internal

Medicine, Institute of Wonkwang

Medical Science, Wonkwang

University School of Medicine,

895 Muwang-ro, Iksan 54538,

Korea

Tel: $+82-63-859-2583$

Fax: $+82-63-855-2025$

E-mail: kshryj@wku.ac.kr
Background/Aims: Brain and bone metastases are common in patients with lung cancer. The development of metastasis is associated with poor survival in lung cancer patients. Although tumor morphologic features on radiographs are routinely assessed for differentiation between benign and malignant lung nodules, they are not used to predict metastasis. We assessed morphologic features of pulmonary adenocarcinomas with brain/bone metastasis on computed tomography (CT) to identify related factors for metastasis.

Methods: We performed a retrospective analysis of initial chest CT findings (size, type of contour, percentage of necrosis, enhancement, presence or absence of calcification, and air cavity) from 2009 to 2010 of patients with brain or bone metastasis and compared the findings with those of patients without metastases.

Results: In total, 128 patients were included ( 78 men, 52 women; mean age 69 years; range, 36 to 87 ). Nineteen patients had brain metastases and 32 had bone metastases. Morphologic features associated with brain metastasis included size $\geq 50 \mathrm{~mm}$ (odds ratio [OR], 3.37; 95\% confidence interval [CI], 1.24 to $9.17 ; p=0.013$ ), necrosis $\geq 30 \%$ (OR, $4.51 ; 95 \% \mathrm{CI}, 1.62$ to $12.55 ; p=0.002$ ), and presence of calcification (OR, 3.97; $95 \%$ CI, 1.16 to 13.55; $p=0.035$ ). Morphologic features associated with bone metastasis included necrosis $\geq 30 \%$ (OR, 4.639; $95 \% \mathrm{CI}, 1.98$ to $10.82 ; p<0.001$ ) and $\mathrm{T} 3$ to 4 stage (OR, $2.53 ; 95 \% \mathrm{CI}, 1.07$ to $6.00 ; p=0.031)$.

Conclusions: We found that necrosis $\geq 30 \%$ was associated with pulmonary adenocarcinoma with brain and bone metastasis at initial chest CT morphologic feature. To validate these results, further research should be conducted.

Keywords: Adenocarcinoma; Computed tomography; Neoplasm metastasis; Morphologic features; Necrosis

\section{INTRODUCTION}

The metastatic spread of cancer to distant organs is the reason for most cancer deaths [1-4]. Lung cancer is the most frequent and among the most lethal types of cancer worldwide. Approximately 50\% of lung cancer cases are metastatic at diagnosis [5]. The major sites of non-small cell lung cancer (NSCLC) metastases include the brain (47\%), bone (36\%), liver (22\%), adrenal glands (15\%), thoracic cavity (11\%), and distant lymph nodes (10\%) [6].

Although morphologic features of tumors on radio- 
graphs are routinely assessed for differentiation between benign and malignant lung nodules, they are not used to predict lung cancer metastasis. There are two significant groups of predictive factors for metastasis: TNM-related factors and tumor-related factors. The TNM-related group comprises information related to tumor size, lymph node, and metastasis factors $[7,8]$, while the tumor-related group comprises histopathological, anatomical, and biochemical factors [9]. On the other hand, morphologic features of tumors that are easily assessed by computed tomography (CT) have not yet been investigated as potential predictive factors for the development of metastasis. In lung cancer, chest CT is routinely used for patient management, including diagnosis, radiation treatment planning, and response evaluation after treatment. In addition, CT is used to evaluate tumor size, lymph node invasion, and metastasis.

Some studies focusing on imaging modalities have suggested that radiologic findings could be a predictive factor for metastasis. However, many of these studies were conducted in patients with resectable early stage lung cancer, so the result cannot be representative of all patients with lung cancer. Among lung cancer, pulmonary adenocarcinomas grow more slowly and form smaller masses than the other subtypes. However, they tend to form metastases widely at an early stage [10]. Thus, we assessed the CT morphologic features of pulmonary adenocarcinomas with brain/bone metastasis with the goal of identifying related factors for metastasis.

\section{METHODS}

We retrospectively reviewed the medical records of 256 patients with lung cancer between January 2009 and December 2010. Only patients with a pathologically confirmed diagnosis of primary pulmonary adenocarcinoma and available CT scans in the Picture Archiving and Communication System were included. Patients were diagnosed with brain metastasis on brain CT or magnetic resonance imaging and bone metastasis on bone scan or positron emission tomography-CT at the time of the initial diagnosis of lung cancer. Ultimately, 128 patients were included in the study. In this study, patients with adrenal gland, liver metastasis were ex-
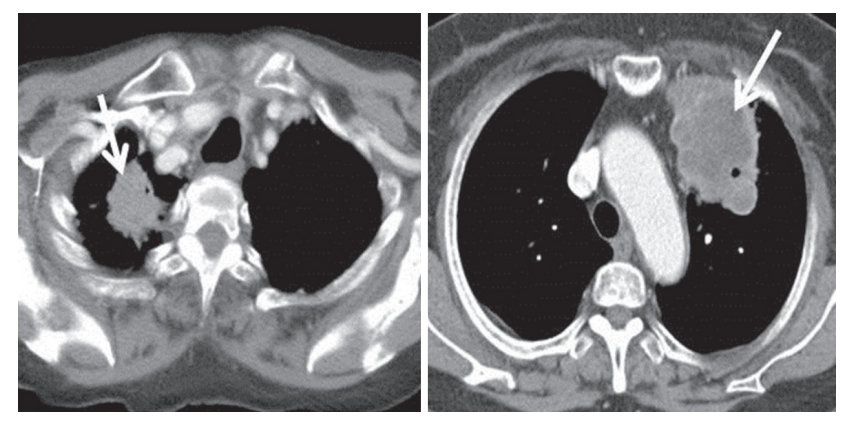

Figure 1. Illustration of computed tomography features of pulmonary adenocarcinoma investigated in this study. (A) Necrosis $(-)$, (B) necrosis (+). Arrow indicates features of interest in each image.

cluded for fewer cases.

We collected clinical data such as age, sex, smoking history, lung cancer staging, and histological type, and CT morphologic features such as size, type of contour, percentage of necrosis, enhancement, presence or absence of calcification, and air cavity.

Two radiologists analyzed the patients' CT morphologic features as if making the initial diagnosis. They did not have any of the patients' data while evaluating the initial chest CT images. Imaging features that are common in lung cancer patients were used as items of CT morphologic findings for subgroup analysis. By comparing pre- and post-enhancement images without delay, we determined a standard site width difference between the enhancement of identical site lesions. With this standard, we defined necrosis as a site of decreased Hounsfield units, similar to the process of fat deposition. Additionally, we separated the findings into two different groups: one with more than $30 \%$ of the lesion occupied by necrosis, and the other with less than $30 \%$ occupied (Fig. 1). Calcification was defined when the CT findings had similarities to bone density. The definition of an air cavity was a gas-filled or air density space within a pulmonary lesion, such as a consolidation, mass, or nodule, and these findings were qualified. Air cavities included air bronchograms and small air spaces in lesions. The type of contour was divided into round, speculated, and linear. TNM staging was performed using the American Joint Committee on Cancer Cancer Staging Manual, 7 th edition.

Statistical analysis of the relationship between each of the variables and the presence of metastasis was per- 
formed using the chi-square test or Fisher exact test. The odds ratio was calculated from the frequency of each of the variables compared between metastasis-positive and metastasis-negative patients. Univariate analysis was first applied to assess the association between each of the variables and mortality. Variables selected by univariate analysis $(p<0.05)$ and those considered as clinically relevant were entered in a logistic regression model. The Kaplan-Meier method and log-rank test were used to perform univariate survival analysis. All statistical analyses were performed with SPSS version 18 (SPSS Inc., Chicago, IL, USA). A value of $p<0.05$ was considered statistically significant.

\section{RESULTS}

\section{Patients}

Materials and data from 78 men (60\%) and 52 women (40\%) were included in the study. The patients ranged in age from 36 to 87 years (median, 69.0). Among the 128 included patients, 60 patients had stage 4 disease, 46 patients had stage 3 , four patients had stage 2 , and 18 patients had stage 1 disease.

Table 1 shows the CT morphologic features of the tumors. The median diameter of all measured tumors was $44.24 \mathrm{~mm}$ (range, 10 to 176 ).

\section{CT morphologic features in brain metastasis group}

Brain metastasis was identified in 19 patients. Table 2 provides information on patient demographics and CT findings at the time of initial diagnosis in the brain metastasis group. By univariate analysis, the brain metastasis group was found to have a significantly higher number of patients with the following characteristics at the time of diagnosis: size $\geq 50 \mathrm{~mm}$ (37.0\% vs. $10.9 \%$ for $<50 \mathrm{~mm}, p=0.013$ ), necrosis $\geq 30 \%$ (40.0\% vs. $5.0 \%$ for $<$ $30 \%, p=0.002$ ), and presence of calcification (50.0\% vs. $14.0 \%$ for absence, $p=0.035$ ).

\section{CT morphologic features in bone metastasis group}

Bone metastasis was identified in 32 patients. Table 3 shows the clinical characteristics and imaging features obtained on chest CT of the patients in the bone metastasis group. By univariate analysis, the bone metastasis group was found to have a significantly higher number
Table 1. Tumor morphologic features in 128 patients with pulmonary adenocarcinoma

\begin{tabular}{lc}
\hline Features and subtype & No. of patients $(\%)$ \\
\hline Size, mm & $90(70)$ \\
$<50$ & $38(30)$ \\
$\geq 50$ & \\
Type of contour & $29(23)$ \\
Round & $61(48)$ \\
Speculated & $38(29)$ \\
\hline Linear & $86(67)$ \\
\hline Necrosis, \% & $42(33)$ \\
\hline 30 & \\
\hline$\geq 30$ & $114(89)$ \\
\hline Calcification & $14(11)$ \\
\hline Absent & \\
\hline Present & $94(73)$ \\
\hline Air cavity & $34(27)$ \\
\hline Absent & \\
\hline Present & \\
\hline
\end{tabular}

of patients with the following characteristics at the time of initial diagnosis: necrosis $\geq 30 \%(82.6 \%$ vs. $17.8 \%$ for $<30 \%, p<0.001)$, and T stage 3 to 4 ( $48.7 \%$ vs. $19.2 \%$ for stage 1 to $2, p=0.031$ ).

\section{Multivariate analysis}

On the basis of the results of univariate analysis, each of the statistically significant variables was subjected to stepwise multivariate analysis. Tables 4 and 5 show the results of multivariate analysis. We identified that necrosis $\geq 30 \%$ was a common related factor for brain and bone metastasis as an initial chest CT morphologic feature. There was no statistically significant correlation of necrosis to patient's survival $(p=0.20)$.

\section{DISCUSSION}

Lung cancer frequently metastasizes to bone, brain, lung, and liver, resulting in shorter survival [11]. Therefore, increased knowledge of metastasis is crucial in the treatment of patients. Previous studies revealed that morphologic features of tumors on radiographs are routinely assessed for differentiation between benign 
Table 2. Morphologic features of pulmonary adenocarcinoma patients with brain metastasis $(+)$ assessed by computed tomography, in comparison to pulmonary adenocarcinoma patients with brain metastasis (-)

\begin{tabular}{lccc}
\hline Variable & $\begin{array}{c}\text { Brain } \\
\text { metastasis }(-)\end{array}$ & $\begin{array}{c}\text { Brain } \\
\text { metastasis }(+)\end{array}$ & p value \\
\hline Age, yr & & & 0.620 \\
$<70$ & 45 & 9 & \\
$\geq 70$ & 64 & 10 & \\
Sex & & & 0.716 \\
Female & 45 & 7 & \\
Male & 64 & 12 & \\
\hline
\end{tabular}

Primary cancer

\begin{tabular}{|c|c|c|c|}
\hline Size, $\mathrm{mm}$ & & & 0.013 \\
\hline$<50$ & 82 & 9 & \\
\hline$\geq 50$ & 27 & 10 & \\
\hline Shape & & & 0.085 \\
\hline Round & 26 & 3 & \\
\hline Speculated & 48 & 13 & \\
\hline Linear & 35 & 3 & \\
\hline Necrosis, \% & & & 0.002 \\
\hline$<30$ & 79 & 7 & \\
\hline$\geq 30$ & 30 & 12 & \\
\hline Calcification & & & 0.035 \\
\hline Absent & 100 & 14 & \\
\hline Present & 9 & 5 & \\
\hline Air cavity & & & 0.086 \\
\hline Absent & 77 & 17 & \\
\hline Present & 32 & 2 & \\
\hline Enhancement & & & 0.467 \\
\hline$<50$ & 38 & 5 & \\
\hline$\geq 50$ & 55 & 14 & \\
\hline \multicolumn{4}{|l|}{ Stage } \\
\hline T stage & & & 0.972 \\
\hline $\mathrm{T}_{1-2}$ & 54 & 8 & \\
\hline $\mathrm{T}_{3-4}$ & 53 & 8 & \\
\hline \multicolumn{4}{|l|}{ N stage } \\
\hline $\mathrm{No}-2$ & 53 & 5 & 0.139 \\
\hline $\mathrm{N}_{3}$ & 56 & 12 & \\
\hline
\end{tabular}

and malignant lung nodules. In the current study, we assessed CT morphologic features of pulmonary adenocarcinomas with brain/bone metastasis to identify predictive factors for metastasis. We found that the features
Table 3. Morphologic features of pulmonary adenocarcinoma patients with bone metastasis $(+)$ assessed by computed tomography, in comparison to pulmonary adenocarcinoma patients with bone metastasis (-)

\begin{tabular}{lccc}
\hline Variable & Bone & Bone & pvalue \\
& metastasis $(-)$ & metastasis $(+)$ & \\
\hline
\end{tabular}

\begin{tabular}{lll}
\hline Age, yr & & \\
$<70$ & 39 & 15 \\
$\geq 70$ & 57 & 17
\end{tabular}

Sex 0.912

$\begin{array}{lll}\text { Female } & 39 & 13 \\ \text { Male } & 65 & 13\end{array}$

Primary cancer

Size, $\mathrm{mm}$

0.091

$\begin{array}{lll}<50 & 72 & 19 \\ \geq 50 & 24 & 13\end{array}$

Shape

0.721

$\begin{array}{lll}\text { Round } & 20 & 6 \\ \text { Speculated } & 48 & 13 \\ \text { Linear } & 28 & 10\end{array}$

Necrosis, \%

$<0.001$

$\begin{array}{lll}<30 & 73 & 13 \\ \geq 30 & 23 & 19\end{array}$

Calcification

0.748

$\begin{array}{lll}\text { Absent } & 86 & 28 \\ \text { Present } & 10 & 4\end{array}$

Air cavity

0.817

$\begin{array}{lll}\text { Absent } & 71 & 23 \\ \text { Present } & 25 & 9\end{array}$

Enhancement

$\begin{array}{lll}<50 & 30 & 13 \\ \geq 50 & 66 & 19\end{array}$

Stage

\begin{tabular}{rrrr} 
T stage & & & 0.031 \\
$\mathrm{~T}_{1-2}$ & 52 & 10 & \\
$\mathrm{~T}_{3}-4$ & 41 & 20 & \\
$\mathrm{~N}$ stage & & & \\
$\mathrm{No}-2$ & 47 & 11 & 0.175 \\
$\mathrm{~N}_{3}$ & 48 & 20 & \\
\hline
\end{tabular}

observed on chest CT most significantly associated with an increased risk of brain metastasis were size $\geq 50 \mathrm{~mm}$, necrosis $\geq 30 \%$, and calcification, and those associated with an increased risk of bone metastasis were necrosis 
Table 4. Variables predictive of brain metastasis on multivariate analysis

\begin{tabular}{|c|c|c|c|}
\hline Variable & Odds ratio & $95 \%$ Confidence interval & $p$ value \\
\hline \multicolumn{4}{|l|}{ Size, mm } \\
\hline$\geq 50$ & $3 \cdot 37$ & $1.24-9.17$ & $<0.05$ \\
\hline \multicolumn{4}{|c|}{ Necrosis, \% } \\
\hline$\geq 30$ & $4 \cdot 51$ & $1.62-12.55$ & $<0.05$ \\
\hline \multicolumn{4}{|c|}{ Calcification } \\
\hline Present & 3.97 & $1.16-13.55$ & 0.073 \\
\hline
\end{tabular}

Table 5. Variables predictive of bone metastasis on multivariate analysis

\begin{tabular}{|c|c|c|c|}
\hline Variable & Odds ratio & $95 \%$ Confidence interval & $p$ value \\
\hline \multicolumn{4}{|l|}{ Size, $\mathrm{mm}$} \\
\hline$\geq 50$ & 2.05 & $0.88-4.77$ & 0.78 \\
\hline \multicolumn{4}{|c|}{ Necrosis, \% } \\
\hline$\geq 30$ & 4.69 & $1.98-10.82$ & $<0.05$ \\
\hline \multicolumn{4}{|c|}{ Calcification } \\
\hline Present & 1.23 & $0.35-4.23$ & 0.97 \\
\hline \multicolumn{4}{|l|}{ T stage } \\
\hline $\mathrm{T}_{3}-4$ & 2.53 & $1.07-6.00$ & $<0.05$ \\
\hline
\end{tabular}

$\geq 30 \%$ and $\mathrm{T}$ stage 3 to 4 . A finding of necrosis $\geq 30 \%$ on chest CT was a common related factor for the development of brain/bone metastasis.

Various studies have proposed a close correspondence between CT morphologic features and prognosis. Takashima et al. [12] demonstrated that the percentage of ground glass opacity (GGO) area measured by high-resolution CT was a significant factor for the survival of lung cancer patients. Aoki et al. [13] showed that the frequencies of lymph node metastasis and vessel invasion in adenocarcinomas with GGO components of more than $50 \%$ were significantly lower than those in adenocarcinomas with GGO components of less than 10\% obtained by thin-section CT findings. There have also been studies focusing on the relationship between CT morphologic characteristics as well as tumor size and TNM grade [14-17]. Bajard et al. [18] showed that clinical $\mathrm{T}$ classification was significant for the development of brain metastasis in a cohort of 305 NSCLC patients. In the current study, $T$ stage was associated with the incidence of bone metastasis. Even though nodal involvement is part of TNM staging, we were unable to find any relationship between CT morphologic features and metastasis in this study.
Some studies, researching prognostic factors rather than predictive factors, found that tumor necrosis was associated with poor outcomes in lung cancer patients. Inoue et al. [19] reported that microscopic necrosis was associated with tumor recurrence, leading to decreased 5-year disease-free survival rates. In another study by Kilicgun et al. [20] and Park et al. [21], the authors reported that tumor necrosis was a significant adverse risk factor for cancer recurrence and was also associated with patients' overall survival $[22,23]$. The majority of results from those studies have statistical significance in terms of prognostic value or patient survival rates, but they are limited to patients with early stage lung cancer and have little to offer regarding predictive value.

Necrosis is associated with an unusual, passive, and unregulated pathway of cell death caused by injury, damage, and ischemia [24]. Death of cells resulting from extreme conditions such as temperature change or inflammatory reaction causes an unregulated process of destruction of cell membranes and the cytosol, and finally cell digestion. Particularly in the case of tumor cell necrosis, a pattern of coagulative change is the most common. This is caused by tissue hypoxemia due to rapid tumor cell growth, incomplete neovascularization, 
and hypoperfusion of adjacent vessels [25-27]. By this mechanism, tumor necrosis measured by CT is the result of a time-dependent element and could play a role as a predictive factor associated with cancer metastasis.

In our study, the presence of an air cavity did not have statistical significance. However, some studies have reported that an air cavity has occurred following tissue necrotic change. A cavity has been defined as a gas-filled space within a pulmonary nodule, mass, or consolidation. It is produced by the expulsion of a necrotic part of a lesion. By this mechanism, necrosis and cavities may have a correlated time-dependent relationship [28]. Some studies have shown that the presence of an air cavity with lung cancer tissue was associated with a greater likelihood of progression to metastasis and recurrence compared to the absence of an air cavity lesion, so patients with an air cavity had poorer overall survival. Although the mechanism of cavity formation is often difficult to ascertain, cavitation in lung cancer most often results from rapid tumor growth that exceeds the blood supply, with the result of central necrosis [29-31]. Therefore, we expect that the presence of cavitation assessed by CT may be another predictive factor for the development of lung cancer metastasis, and the question should be further investigated through prospective studies with large numbers of patients and long-term follow-up.

The present study has several limitations, including the retrospective observational design, leading to the possibility that selection bias influenced the significance of our findings. Our study is also from a single institution and has a small sample size, factors which limit the generalizability of our findings to other institutions. In addition, evaluation of the percentage of necrosis would involve artifactual variations between pre- and post-enhancement in relation to a modality quality factor. Further research, using computer aided medical image diagnosis system, should be conducted to assess additional related factors for metastasis and survival in lung cancer.

In conclusion, features observed on chest CT most significantly associated with an increased risk of brain metastasis were size $\geq 50 \mathrm{~mm}$, necrosis $\geq 30 \%$, and calcification, and those associated with an increased risk of bone metastasis were necrosis $\geq 30 \%$ and $\mathrm{T}$ stage 3 to 4 . A finding of necrosis $\geq 30 \%$ on chest CT was a common related factor for the development of brain/bone metastasis. To validate these results, further research should be conducted.

\section{KEY MESSAGE}

1. In this study, we assessed computed tomography (CT) morphologic features of pulmonary adenocarcinomas with brain/bone metastasis to identify predictive factors for metastasis. A finding of necrosis $\geq 30 \%$ on chest CT was a common related factor for the development of brain/bone metastasis.

2. Further research, using computer aided medical image diagnosis system, should be conducted to assess additional related factors for metastasis and survival in lung cancer.

\section{Conflict of interest}

No potential conflict of interest relevant to this article was reported.

\section{Acknowledgments}

This study was supported by a grant of the Korean Health Technology R\&D Project, Ministry of Health and Welfare, Republic of Korea (H12CO110), and a grant of the Korea Health Technology R\&D Project through the Korea Health Industry Development Institute (KHIDI), funded by the Ministry of Health and Welfare, Republic of Korea (grant number: HI15C1951).

\section{REFERENCES}

1. Langley RR, Fidler IJ. Tumor cell-organ microenvironment interactions in the pathogenesis of cancer metastasis. Endocr Rev 2007;28:297-321.

2. Langley RR, Fidler IJ. The seed and soil hypothesis revisited: the role of tumor-stroma interactions in metastasis to different organs. Int J Cancer 2011;128:2527-2535.

3. Chen LL, Blumm N, Christakis NA, Barabasi AL, Deisboeck TS. Cancer metastasis networks and the prediction of progression patterns. Br J Cancer 2009;101:749-758.

4. Kakiuchi S, Daigo Y, Tsunoda T, Yano S, Sone S, Nakamura Y. Genome-wide analysis of organ-preferential metastasis of human small cell lung cancer in mice. Mol Cancer Res 2003;1:485-499.

5. Bains MS. Surgical treatment of lung cancer. Chest 1991;100:826-837.

6. Perisano C, Spinelli MS, Graci C, et al. Soft tissue metastases in lung cancer: a review of the literature. Eur Rev 
Med Pharmacol Sci 2012;16:1908-1914.

7. Port JL, Kent MS, Korst RJ, Libby D, Pasmantier M, Altorki NK. Tumor size predicts survival within stage IA nonsmall cell lung cancer. Chest 2003;124:1828-1833.

8. Chang MY, Mentzer SJ, Colson YL, et al. Factors predicting poor survival after resection of stage IA non-small cell lung cancer. J Thorac Cardiovasc Surg 2007;134:850-856.

9. Huang C, Liu D, Masuya D, et al. Clinical application of biological markers for treatments of resectable nonsmall-cell lung cancers. Br J Cancer 2005;92:1231-1239.

10. Maitra A, Kumar V. Box on morphology of adenocarcinoma. In: Kumar V, Abbas AK, Fausto N, Mitchell R, eds. Robbins Basic Pathology. 8th ed. Philadelphia: Saunders, 2007:479-540.

11. Hess KR, Varadhachary GR, Taylor SH, et al. Metastatic patterns in adenocarcinoma. Cancer 2006;106:1624-1633.

12. Takashima S, Maruyama Y, Hasegawa M, et al. Prognostic significance of high-resolution CT findings in small peripheral adenocarcinoma of the lung: a retrospective study on 64 patients. Lung Cancer 2002;36:289-295.

13. Aoki T, Tomoda Y, Watanabe H, et al. Peripheral lung adenocarcinoma: correlation of thin-section CT findings with histologic prognostic factors and survival. Radiology 2001;220:803-809.

14. Jiang B, Takashima S, Miyake C, et al. Thin-section CT findings in peripheral lung cancer of $3 \mathrm{~cm}$ or smaller: are there any characteristic features for predicting tumor histology or do they depend only on tumor size? Acta Radiol 2014;55:302-308.

15. Asamura H, Suzuki K, Watanabe S, Matsuno Y, Maeshima A, Tsuchiya R. A clinicopathological study of resected subcentimeter lung cancers: a favorable prognosis for ground glass opacity lesions. Ann Thorac Surg 2003;76:1016-1022.

16. Tateishi M, Fukuyama Y, Hamatake M, et al. Characteristics of non-small cell lung cancer $3 \mathrm{~cm}$ or less in diameter. J Surg Oncol 1995;59:251-254.

17. Alexander BM, Othus M, Caglar HB, Allen AM. Tumor volume is a prognostic factor in non-small-cell lung cancer treated with chemoradiotherapy. Int J Radiat Oncol Biol Phys 2011;79:1381-1387.

18. Bajard A, Westeel V, Dubiez A, et al. Multivariate analysis of factors predictive of brain metastases in localised nonsmall cell lung carcinoma. Lung Cancer 2004;45:317-323.

19. Inoue M, Takakuwa T, Minami M, et al. Clinicopathologic factors influencing postoperative prognosis in patients with small-sized adenocarcinoma of the lung. J Thorac
Cardiovasc Surg 2008;135:830-836.

20. Kilicgun A, Turna A, Sayar A, Solak O, Urer N, Gurses A. Very important histopathological factors in patients with resected non-small cell lung cancer: necrosis and perineural invasion. Thorac Cardiovasc Surg 2010;58:93-97.

21. Park SY, Lee HS, Jang HJ, Lee GK, Chung KY, Zo JI. Tumor necrosis as a prognostic factor for stage IA nonsmall cell lung cancer. Ann Thorac Surg 2011;91:1668-1673.

22. Swinson DE, Jones JL, Richardson D, Cox G, Edwards JG, O'Byrne KJ. Tumour necrosis is an independent prognostic marker in non-small cell lung cancer: correlation with biological variables. Lung Cancer 2002;37:235-240.

23. Takahashi Y, Akishima-Fukasawa Y, Kobayashi N, et al. Prognostic value of tumor architecture, tumor-associated vascular characteristics, and expression of angiogenic molecules in pancreatic endocrine tumors. Clin Cancer Res 2007;13:187-196.

24. Gkogkou C, Frangia K, Saif MW, Trigidou R, Syrigos K. Necrosis and apoptotic index as prognostic factors in non-small cell lung carcinoma: a review. Springerplus 2014;3:120.

25. Dworakowska D, Jassem E, Jassem J, et al. Prognostic value of the apoptotic index analysed jointly with selected cell cycle regulators and proliferation markers in nonsmall cell lung cancer. Lung Cancer 2009;66:127-133.

26. Edinger AL, Thompson CB. Death by design: apoptosis, necrosis and autophagy. Curr Opin Cell Biol 2004;16:663669.

27. Langendijk H, Thunnissen E, Arends JW, et al. Cell proliferation and apoptosis in stage III inoperable non-small cell lung carcinoma treated by radiotherapy. Radiother Oncol 2000;56:197-207.

28. Gadkowski LB, Stout JE. Cavitary pulmonary disease. Clin Microbiol Rev 2008;21:305-333.

29. Watanabe Y, Kusumoto M, Yoshida A, Suzuki K, Asamura $\mathrm{H}$, Tsuta K. Surgically resected solitary cavitary lung adenocarcinoma: association between clinical, pathologic, and radiologic findings and prognosis. Ann Thorac Surg 2015;99:968-974.

30. Onn A, Choe DH, Herbst RS, et al. Tumor cavitation in stage I non-small cell lung cancer: epidermal growth factor receptor expression and prediction of poor outcome. Radiology 2005;237:342-347.

31. Sugimoto Y, Semba H, Fujii S, Furukawa E, Kurano R. Clinical analysis of primary lung cancer with a thin-walled cavity to explain the mechanism of thin-walled cavity formation. Nihon Kokyuki Gakkai Zasshi 2007;45:460-464. 